\title{
Proyecto moral de Theodor $W$. Adorno después de Auschwitz
}

\author{
Arlex Berrio Peña
}

Grupo de Investigación Studia

Universidad del Norte

Colombia

doi: http://dx.doi.org/10.18273/revfil.v18n2-2019008 (c) († 


\section{Proyecto moral de Theodor W. Adorno después de Auschwitz}

Resumen: este artículo rastrea las categorías del proyecto moral de Adorno a partir de la barbarie experimentada en los campos de concentración nazi durante la Segunda Guerra Mundial. Para ello, el autor utiliza la estrategia de pensar la filosofía a partir del modelo de la Teoría Crítica de la Escuela de Fráncfort . Este novedoso proyecto orienta al hombre o cualquier idea de filosofía y ética con sentido, atendiendo nuevas categorías de la realidad fáctica. Concretamente, Adorno construye un proyecto moral que tiene como fundamento, primero, un nuevo marco para la metafísica y antropología a partir de Auschwitz y, segundo, direccionado a evitar que nuevas expresiones de barbarie como esta se repitan. Adorno expone las categorías éticas en Meditaciones sobre la metafísica en su obra Dialéctica Negativa.

Palabras clave: ética, barbarie, categorías de la razón, realidad fáctica, Dialéctica Negativa, ética de la resistencia, metafísica, subjetividad.

\section{Project of Theodor W. Adorno after Auschwitz}

Abstract: this article traces the categories of Adorno's moral project from the barbarism experienced in the nazi concentration camps during the Second World War. For this, the author uses the strategy of thinking philosophy from the model of the Critical Theory of The Frankfurt School. This novel project orients to the man or any idea of philosophy and ethics with sense, taking care of new categories of the factual reality. Specifically, Adorno builds a moral project that has as its foundation, first, a new framework for metaphysics and anthropology from Auschwitz and, second, aimed at preventing new expressions of barbarism like this from repeating themselves. Adorno exposes the ethical categories in Meditations on metaphysics in his work Negative Dialectics.

Keywords: ethics, barbarism, categories of reason, factual reality, Negative Dialectics, ethics of resistance, metaphysics, subjectivity.

Fecha de recepción: 26 de julio de 2018

Fecha de aceptación: 19 de noviembre de 2018

Forma de citar (APA): Berrio-Peña, A. (2019). Proyecto moral de Theodor W. Adorno después de Auschwitz. Revista Filosofía UIS, 18(2), doi: 10.18273/revfil.v18n2-2019008

Forma de citar (Harvard): Berrio-Peña, A. (2019). Proyecto moral de Theodor W. Adorno después de Auschwitz. Revista Filosofía UIS, 18(2), 143-165.

Arlex Berrio Peña: colombiano. Magíster en Filosofía. Investigador de la Universidad del Norte.

Correo electrónico: arlex_berrio@hotmail.com

ORCID: 0000-0002-9841-5399

*Artículo de reflexión derivado de investigación. 


\section{Proyecto moral de Theodor W. Adorno después de Auschwitz ${ }^{* *}$}

\section{Introducción}

Para los autores de Dialéctica de la llustración las expresiones de violencia que se manifestaron en los campos de concentración, durante la segunda guerra mundial, se convirtieron en un novedoso escenario capaz de ser comprendido dentro un marco filosófico. No se trataba de comprender históricamente cómo y por qué se Ilegó a tales acciones atroces, sino reflexionar, a través de un ejercicio filosófico, las tesis que respaldan, coinciden y permiten que hechos tan lamentables ocurran, y buscar mecanismos para evitar que algo parecido pueda repetirse.

Con este nuevo panorama, el campo de concentración de Auschwitz ${ }^{1}$ se convierte en el filtro para examinar todo lo que la racionalidad occidental ha construido a través la historia, según Horkheimer y Adorno. No se trata simplemente de poner a prueba los aportes realizados por la filosofía, sino entender cómo, a pesar de ello, la barbarie fue y ha sido posible en nuevas formas de expresión y la filosofía poco o nada ha podido hacer para evitarlo.

Auschwitz, según Adorno y Horkheimer, confirma la anulación del sujeto y cualquier posibilidad de metafísica idealista. Las consecuencias de estas tesis son absolutamente graves porque el hombre, según los frankfurtianos, al estar anulado, queda en el centro de un problema donde no hay posibilidad de encontrar rastros de humanidad en sí mismo y la realidad, bajo presupuestos idealistas, lo conduce a la construcción de un mundo ajeno así mismo. En este sentido, si Auschwitz afirma la anulación de la subjetividad, todo acto realizado por el hombre contra la naturaleza y contra sí mismo se justifica y la metafísica tradicional lo fundamenta.

\footnotetext{
**Esta reflexión es parte del proyecto de investigación del autor para alcanzar el título de Maestría en la Universidad del Norte (Barranquilla, Colombia). Trabajo que se titula: "La superación de la barbarie, la emancipación del sujeto, y la autorreflexión crítica; fines del proyecto educativo en Theodor Adorno".

${ }^{1}$ Auschwitz es el nombre de un campo de concentración nazi que, para los autores de la Teoría Crítica, es el signo por excelencia con el que la barbarie, en los tiempos modernos, se manifiesta. No existe mejor evento histórico para comprender las nuevas manifestaciones de la barbarie. De este modo, Auschwitz es una manera de nombrar toda forma de manifestación violenta.
} 
Sin embargo, para Horkheimer y Adorno no se trata de condenar la historia de la humanidad a una ruina eterna, porque consideran que debe existir alguna posibilidad para salir de esta aporía. En el caso de Adorno, un proyecto moral para superar esta situación debe partir de una nueva idea de filosofía después de Auschwitz. Es decir, se orienta concretamente en la formulación novedosa del imperativo categórico que tiene por referencia a Auschwitz. Por esta razón, en Meditaciones sobre la metafísica, apartado de la Dialéctica Negativa, Adorno no solo reconoce la profundidad y complejidad de Auschwitz, sino que descubre un espejo donde la humanidad puede observar, de forma retrospectiva y reconstructiva, la expresión de la racionalidad en su forma instrumental y las consecuencias que ello implica para preguntas tan fundamentales para la filosofía como la del sentido. Por esta razón, Adorno afirma: "[...] el último capítulo [refiriéndose a Dialéctica Negativa] gira y tantea alrededor de las preguntas metafísicas, en el sentido de que la autorreflexión crítica hace a su vez revoluciones a la revolución copernicana" (1975, p. 9). Pero, ¿qué categorías anuncia Adorno para la construcción de un proyecto moral que consiga la resignificación de la subjetividad y la metafísica después de Auschwitz?

Para comprender esta propuesta moral, en el sistema de pensamiento de Adorno, se ha dispuesto, primero, entender el significado de Auschwitz como expresión de la Dialéctica de la Ilustración. Segundo, concretizar los alcances de Auschwitz en la anulación de la subjetividad y la metafísica. Tercero, rastrear y reflexionar las nuevas categorías del proyecto moral después de Auschwitz a través de la propuesta ética que Adorno enuncia en el capítulo Meditaciones sobre la metafísica de la obra Dialéctica Negativa, teniendo en cuenta, como marco de referencia, los análisis y aportes realizados por Martha Tafalla y Bernstein.

\section{Auschwitz como expresión de la Dialéctica de la llustración}

En Dialéctica de la Ilustración Horkheimer y Adorno realizan un estudio sobre el antisemitismo pensado a partir de Auschwitz. Para ambos autores este acontecimiento, por sus características, sobretodo político-social, ayuda a comprender la violencia extrema de la sociedad moderna y "[...] la crueldad que brota de la civilización fracasada" (Horkheimer y Adorno, 1998, p. 156)². De acuerdo con esta tesis, el antisemitismo no se entiende simplemente como una situación histórica que explica el destino de lo judío, sino que es la categoría más apropiada para explicar la violencia pensada, planificada y ejecutada por la sociedad moderna, no solo contra un pueblo y unos sujetos en particular, sino contra la especie humana en general ${ }^{3}$.

\footnotetext{
${ }^{2}$ Según Geyer para Horkheimer y Adorno "Auschwitz es el testimonio inmediato de la correlación de la tesis básica de la reconstrucción de la historia [...] según la cual la civilización provoca lo anticivilizador (lo destructivo) y lo refuerza a través del curso de la historia" (1985, p. 138).

${ }^{3}$ Para Barahona, el antisemitismo, comprendido en los términos de Horkheimer y Adorno, es la última
} 
Las nuevas formas de barbarie que se experimentan en la modernidad son analizadas a través un acontecimiento histórico que pone en evidencia la decadencia de la civilización. De allí que, para Horkheimer y Adorno, el antisemitismo represente, a través de Auschwitz, una expresión de la Dialéctica de la Ilustración que demuestra el retorno de la barbarie, la recaída de la civilización (cfr. Escobar, 2009, p. 4). En este sentido, Auschwitz es un síntoma que permite rastrear la decadencia de la historia de la racionalidad occidental.

Al respecto, Stefan Gandler considera que el antisemitismo acontecido en la cima de la civilización moderna no debe asumirse como un 'accidente de la historia'. Por el contrario, es la demarcación y cumplimiento de la 'marcha lógica' de la misma. Es una condena calculable de la barbarie que solo es posible encontrar en los campos de concentración nazis (cfr. Gandler, 2009).

El antisemitismo es la expresión de la racionalidad enferma que —en la lógica fascista - condena el proyecto de la llustración de la humanidad a su pérdida total. En la imagen del judío se entrevé una especie de chivo expiatorio que recoge la condena del hombre moderno y, motivado por las desgracias del capitalismo, se convierte, como expresa Adorno, en el elemento de cuya eliminación dependerá la felicidad de todos (cfr. Horkheimer y Adorno, 1998). Sin embargo, Adorno afirma:

No se puede poner a Auschwitz en analogía con la aniquilación de las Ciudades-Estado griegas no viendo más que un mero aumento gradual del horror, una analogía con la que conservar la paz del alma. Pero es innegable que los martirios y humillaciones jamás experimentados antes de los que fueron transportados en vagones para el ganado arrojan una intensa y mortal luz sobre aquel remoto pasado, en cuya violencia obtusa y no planificada estaba ya teleológicamente implícita la violencia científicamente concebida (1998, p. 237).

No son comparables atrocidades, ni actos de barbarie en la historia solo por datos estadísticos; el aumento del sufrimiento de los seres humanos no es reducible a lo matematizable y calculable. Aunque las formas de violencia experimentadas antes de lo vivido en los campos de concentración no se pueden comparar de modo exacto y lineal con el fenómeno presentado en esa experiencia particular, sí pueden ser relacionadas con este, pues existe una expresión de la violencia irracional de la modernidad, presente incluso en formas de violencia acontecidas previamente en la historia.

\footnotetext{
consecuencia de la razón enferma que ha ido imponiéndose progresivamente en el tiempo hasta controlar todas las esferas de la vida humana, la naturaleza, la individualidad, las relaciones entre los hombres. Por eso, es la expresión de la Dialéctica de la llustración. De este modo, el antisemitismo evidencia la aniquilación del individuo y la sociedad, en el plano teórico y práctico, de manera cruel y despiadada en tiempos modernos (cfr. Barahona, 1996, p. 180).
} 


\section{Auschwitz: anulación de la subjetividad y la metafísica}

Para Adorno, el antisemitismo en Auschwitz pone en evidencia la anulación de toda pretensión de subjetividad. La subjetividad marcada por la irracionalidad es la manifestación concreta de la construcción de un sujeto vacío de racionalidad. De hecho, en La personalidad autoritaria se expresa: "El antisemitismo se basa más en factores del sujeto y en su situación global que en las características reales de los judíos" (Adorno, Frenkel, Levinson y Nevitt, 1965, p. 28). Según esta expresión, el problema no es ni siquiera contra los judíos, sino con la idea de sujeto.

La interpretación de Adorno sobre el antisemitismo está relacionada con "[...] la idea de la destrucción del individuo en las sociedades avanzadas" (López, 2011, p. 33). Coincide con esta tesis, en Crítica de la razón instrumental, Horkheimer al afirmar: "La transformación total de todo dominio ontológico en un dominio de medio, llevada a cabo realmente, conduce a la liquidación del sujeto" (1973, p. 103).

Para Adorno, el antisemitismo de Auschwitz, como expresión de la negación de la subjetividad, no solo es una expresión metafórica, potencialidad literaria, sino que es una de las mayores evidencias en la historia y en el pensamiento declive y de la homogenización de los seres humanos como iguales.

Por otro lado, en las primeras páginas de la obra Dialéctica Negativa, Adorno escribe en su reflexión sobre la dialéctica, un análisis de lo que ha hecho la filosofía, a través de la historia, por tratar de fusionar teoría y praxis. Respecto a dicha función afirma: "Tal vez la interpretación que prometió una transición a la praxis fue insuficiente" (Adorno, 1975, p. 11). Según el autor, el quehacer filosófico ha fijado una deuda epistemológica al no poder aunar el mundo del pensamiento con el mundo natural. El pensamiento ha quedado reducido a la identificación del mundo del sujeto con el de los objetos, y el orden conceptual se impone satisfactoriamente ante lo que el pensamiento trata de comprender (cfr. Adorno, 1975, p. 13). Al respecto, Adorno afirma:

Esta contradicción de la separación entre sujeto y objeto se comunica a la teoría del conocimiento. En efecto, no se les puede dejar de pensar como separados [...] ambos se encuentran mediados recíprocamente. [...] Tan pronto como es fijada sin mediación, esa separación se convierte en ideología [...] una vez separado el sujeto radicalmente del objeto, lo reduce así; el sujeto devora al objeto en el momento que olvida hasta qué punto él mismo es objeto (1993, p. 148).

La crítica de Adorno en Dialéctica Negativa está directamente relacionada con la tendencia de la racionalidad a construir el mundo a partir del sujeto, utilizando la naturaleza como medio de identificación con sus ideas. Por esta razón, al 
referirse a la racionalidad tradicional Adorno expresa: "[...] en cuanto dialéctica idealista, se encontraba remachada con el predominio del sujeto absoluto, y este era la fuerza que operaba negativamente. La historia ha condenado un tal predominio del sujeto" (1975, p. 14). El predominio del sujeto para construir y dominar el medio ha sido lo que ha determinado la metafísica. De allí que la metafísica, como expresión del idealismo, que mantiene en todos sus niveles la infinitud propia del carácter positivista de la realidad, reafirma la constitución de la razón como principio del yo que no encuentra límites en ninguna esfera (cfr. Adorno, 1975, p. 34). La evidencia de esta disyuntiva, respecto a la metafísica, es explicitada por Adorno de la siguiente manera: "El terremoto de Lisboa bastó para curar a Voltaire de la teodicea leibniziana; pero la abarcable catástrofe de la primera naturaleza fue insignificante comparada con la segunda, social, cuyo infierno real a base de maldad humana sobrepasa nuestra imaginación" (1975, pp. 361-362).

Al relacionar esta postura con Auschwitz, Adorno afirma: "[...] si la capacidad de metafísica ha quedado paralizada, es porque lo ocurrido le deshizo al pensamiento metafísico especulativo la base de su compatibilidad con la experiencia" (1975, p. 362). Es decir, hay una parálisis que irrumpe en la cotidianidad de la existencia para reflexionar y pensar nuevamente el mundo de la experiencia que Auschwitz y las nuevas formas de barbarie niegan ${ }^{4}$. Por ende, debe existir la posibilidad de una dialéctica que reconcilie metafísica y experiencia.

Para Muñoz esta pretensión puede ser posible en la medida que exista vinculación entre experiencia y pensamiento. De allí que manifieste:

[...] el pensamiento filosófico quiere —incluso debe- ser metafísico. Pero para ello debe, si no quiere quedar reducido a mero idealismo, referirse a la experiencia en el sentido lato, cuanto menos, de nuestra experiencia global del mundo. Y a la vez, sin embargo, lo que experimenta el pensamiento filosófico de nuestra época —-Auschwitz como el infierno real- ya no le permite producir ideas metafísicas (2011, p. 21).

La posibilidad de la metafísica, como expresión del pensamiento filosófico, no puede establecerse como idealismo, aunque las expresiones modernas de la barbarie permitan dudar de ello ${ }^{5}$. Sin embargo, lo que no se puede dejar de

\footnotetext{
${ }^{4}$ Para Horkheimer "Las torturas desbordan la capacidad de imaginación y pensamiento: el pensamiento que intentó seguir el crimen se queda estupefacto de espanto, y se vuelve impotente" (2000, p. 114). ${ }^{5}$ Horkheimer en uno de los aforismos de Ocaso, titulado Metafísica, propone una idea más que provocadora: la metafísica es la expresión del lenguaje pomposo de los doctos señores. Puede que intente describir el conocimiento de la esencia verdadera de las cosas. Precisamente en el ámbito académico se ha realizado, a partir de esta idea de metafísica, una experiencia de contemplación de lo real, sin una aproximación a las contradicciones del sistema social. Incluso se habla de los principios de una comunidad ideal, pero nada o poco se dice respecto a las relaciones sociales en su aspecto histórico y material. Horkheimer afirma: "Yo no sé en qué medida tienen razón los metafísicos; tal vez hay en alguna parte un sistema metafísico, o un fragmento suyo, especialmente acertado, pero sí sé
} 
reconocer es que, según esta afirmación, la experiencia de Auschwitz, hace del pensamiento una categoría que permite un momento de reflexión dialéctica de la racionalidad contra sí misma. Si la metafísica ha quedado anulada en Auschwitz es porque la barbarie experimentada no solo hizo posible comprobar la anulación de la experiencia, sino también la anulación de toda posibilidad de relación entre realidad y pensamiento.

\section{4. Ética de la no-identidad; ética de la resistencia}

Adorno en el capítulo Meditaciones sobre la metafísica ${ }^{6}$, tercera parte de Dialéctica Negativa, empieza su reflexión con un apartado que titula: Después de Auschwitz. En las primeras líneas de este expresa:

[...] la sensibilidad no puede menos de ver en toda afirmación de la positividad de la existencia una charlatanería, una injusticia para con las víctimas, y tiene que revelarse contra la extradición de un sentido, por abstracto que sea, de aquel trágico destino (1975, p. 361).

De algún modo, el autor otorga sentido a la sensibilidad como fundamento del proyecto ético luego del acontecimiento de Auschwitz. En esta idea de filosofía, que prioriza lo sensible, encuentra en el sufrimiento de los cuerpos, la experiencia del dolor y del mal un elemento que se constituye en punto de partida para pensar una reflexión ética que localiza su justificación en una experiencia que se aleja del idealismo y se enfoca en las condiciones de la realidad fáctica. Por consiguiente, partir de lo que acontece a los cuerpos posibilita pensar más allá de una metafísica idealista y abre un horizonte para que el sujeto se enfrente a realidades concretas, dolorosas y traumáticas. Al respecto, Tafalla manifiesta:

Ante el dolor ajeno, lo primero que reacciona no es la racionalidad, sino nuestro cuerpo, sacudido por el dolor de los cuerpos ajenos. Ese sentirse afectado por el dolor de los otros, esa reacción impulsiva y corporal, es lo que Adorno denomina mimesis (2003, p. 62).

El impulso mimético es una manera de afrontar una subjetividad que se encuentra bajo la sombra de la racionalidad instrumental. En relación con esta idea, Schopenhauer había afirmado en El mundo como voluntad y representación:

que los metafísicos, por lo general, sólo en mínima medida, están preocupados por lo que atormenta a los hombres" (1986, p. 64).

${ }^{6}$ Para Cho, si no se analiza Meditaciones sobre la metafísica de Adorno, en Dialéctica Negativa, no se podrá comprender el paso de la filosofía, como simple especulación metafísica a práctica material. Es decir, es el trabajo por excelencia donde Adorno mejor expone el advenimiento del materialismo como nueva forma de metafísica (cfr. Cho, 2009). 


\begin{abstract}
[...] el teórico, traduce la vida en conceptos... son los más felices, no obstante falta mucho para que se logre la perfección en este aspecto y la razón utilizada correctamente pueda realmente liberarnos de todos los vicios y los sufrimientos de la vida, y conducirnos a la felicidad. Antes bien, hay una completa contradicción en querer vivir sin sufrir... Esa contradicción se manifiesta ya en aquella ética de la pura razón... para el caso de que los sufrimientos corporales, que no pueden superarse con ningún principio ni razonamiento filosófico, se vuelvan insuperables e incurables; de modo que su único fin, la felicidad, resulta frustrado y para escapar del sufrimiento no queda más que la muerte, la cual debe entonces tomarse con indiferencia como cualquier otro medicamento (2009, p. 142, nota 108$)$.
\end{abstract}

Adorno se acerca a esta idea de Schopenhauer para esbozar su crítica a la filosofía racionalista que se puso de espaldas al sufrimiento humano, en los siguientes términos: "Aquí se podría buscar una explicación para el hecho que asombró a Schopenhauer de lo débil que es muchas veces la reacción afectiva no solo ante la muerte de otros, sino ante la de uno mismo" (Adorno, 1975, p. 363).

En este sentido, y con base en Schopenhauer, se reconoce la debilidad de una racionalidad que se expresa como irracional y fría ante la experiencia de la violencia y el sufrimiento. De este modo, después de Auschwitz, la reflexión ética mira de frente a estas expresiones de la racionalidad y opta por una postura que busca "[...] ejercer la crítica" (Tafalla, 2003, p. 75). A través de la crítica el sujeto comprende su condición en un mundo adverso a la experiencia humana y estatizado por una metafísica tradicional en la que, según expresa la inteligibilidad kantiana, solo existe el sujeto en su capacidad de ser en su racionalidad.

Cabe preguntarse: ¿de qué manera Adorno responde a la lógica de la metafísica tradicional? En Metafísica y cultura, de Meditaciones sobre la metafísica, el frankfurtiano manifiesta: "La moral no sobrevive más que en el materialismo sin tapujos" (Adorno, 1975, p. 365). La importancia del materialismo radica en que plantea la posibilidad de reconocer en la experiencia humana no solo la racionaliza el mundo, sino que existe un momento material que no es manifestación de un carácter espiritual, ni tampoco se limita al interés de racionalizarse (cfr. Tafalla, 2003, p. 80). Así planteado, una nueva orientación ética y un novedoso perfil del materialismo ofrecen un camino para que haya un desplazamiento de una idea de filosofía hacia una actitud crítica y negativa que le permite al sujeto descubrirse a sí mismo en su materialidad, lo cual no se reduce al encuentro con objetos para ser estudiados, sino que se incorpora en la experiencia humana, en el reconocimiento de sus impulsos, deseos y afectos acompañados de sus facultades racionales. Por ello Adorno afirma "[...] la metafísica sólo puede ganar si se pierde ella misma, es dirigirse a esa otra verdad" (1975, p. 365). La otra verdad se refiere a lo que la racionalidad ha negado en el objeto y que solo ve como posibilidad para dominar. 
El imperativo categórico que germina en Metafísica y cultura es el corazón de la propuesta ética de Adorno. Se trata de un nuevo imperativo que discrepa del kantiano, pues "[...] pretende erigirse como ley moral para los supervivientes de la catástrofe en que pereció la filosofía ilustrada" (Tafalla, 2003, p. 54). En la afirmación de Adorno: "Hitler ha impuesto a los hombres un nuevo imperativo categórico para su actual estado de esclavitud: el de orientar su pensamiento y acción de modo que Auschwitz no se repita, que no vuelva a ocurrir nada semejante" (1975, p. 365), no se expresa una regulación para la acción humana a partir de categorías universales y racionales, tal como se había hecho en los ideales ilustrados, en cuyo carácter apriorístico se afirma toda separación con la experiencia situada e histórica de los seres humanos, sino que se le da un lugar particular a la experiencia humana; sobre todo aquella que se rastrea en el sufrimiento. Después de Auschwitz, la idea de moral kantiana se derrumba porque "El nuevo imperativo categórico no nos lo dicta el conocimiento del bien, sino la voz del mal [...] Demasiados ideales deslumbrantes nos cegaron ya para conducirnos a la catástrofe" (Tafalla, 2003, pp. 58-59). En este horizonte moral el privilegio no lo tiene la razón, sino el cuerpo, sus voces, su experiencia; categorías como la universalidad se expresan como corporalidad.

Se trata de un imperativo que brota al frente de las fosas comunes de los cuerpos humanos que han sido torturados y silenciados. Se trata de un imperativo categórico que tiene sentido en la urgencia de ocuparse de las expresiones de la experiencia humana en el cuerpo: el dolor, la enfermedad, la violencia, la muerte, etc. Ahora la filosofía moral ha encontrado un nuevo horizonte de sentido, su voz tiene matices que antes no se habían contemplado. Sin duda, en este planteamiento Adorno esboza la necesidad de una transformación radical de la metafísica. La fundamentación moral no es afirmativa, se plantea al modo de una teodicea negativa que no confía en el principio de identidad. El imperativo categórico se afirma en lo que debe negarse porque no debe existir posibilidad para que lo que ha negado la humanidad y su experiencia vuelva a repetirse (cfr. Bernstein, 2001, p. 381). Pero mientras se comprende humanamente por qué ocurrió Auschwitz, el imperativo categórico permite que se organice el pensamiento y se oriente la acción para que los hechos que fueron afirmados como muerte y desconocimiento de la dignidad humana sean objeto de la crítica y esta negativa para que nada semejante vuelva a suceder.

Para ello se plantea la necesidad de cambiar el horizonte de toda reflexión sobre la existencia como una ética de la resistencia. El punto crítico a este llamado lo propone Adorno cuando afirma: "Al mismo tiempo que los fascistas tronaban contra el destructivo bolchevismo cultural, Heidegger hacía presentable en sociedad la destrucción como una medida para adentrarse en el ser" (1975, p. 368), pues se llama la atención sobre un modo de reflexión que se ha equivocado en su forma de comprender la existencia. La pregunta no debe plantearse en términos de por qué existe algo y no la nada, sino por qué vive alguien y otro no. 
La vida no se define como regalo, privilegio, don o momento de salvación, sino como sentimiento de culpa que surge porque se vive a costa de otro que sacrificó su vida. "iQué culpa tan radical la del que se salvó!" (Adorno, 1975, p. 363). La existencia no es un objeto de estudio en la lógica de los sistemas idealistas de la metafísica tradicional porque "El respeto a las víctimas impide contestar afirmando sentido de la existencia" (Tafalla, 2003, p. 51). Por eso, después de Auschwitz, no se puede seguir hablando de vida, sino de supervivencia.

Para Bernstein la ética de la supervivencia implica el reconocimiento de lo sucedido como un proceso histórico que debe ser narrado, escrito, documentado sin omitir el registro del nombre de cada una de las víctimas. Si en la inteligibilidad de Auschwitz se ejemplificó la destrucción de la individualidad y se particularizó el desencantamiento del mundo y la instrumentalización de la razón, así como el desconocimiento de las víctimas y su sentido como personas, entonces la rutinización de esas prácticas se convierte en insumo de la crítica para que la discusión moral no se vea abocada a la realización de prácticas contables de cuerpos que fueron marcados y desmembrados (cfr. Bernstein, 2001).

De este modo, la ética se plantea como filosofía primera: las víctimas deben ser reconocidas por su nombre, su historia, su vida y su martirio. Las fosas comunes obligan a pensar que lo sucedido no puede volver a suceder porque las víctimas recuperan su rostro y se constituyen en el centro de toda narración de lo sucedido. Si no se puede escribir poesía después de Auschwitz, como afirmó Adorno, es porque es imposible erigir un significado para la muerte si no a partir de una lectura de la banalidad del mal. Como afirma Bernstein en su propuesta, al deshacerse la distinción categorial entre la vida y la muerte, los nazis igualmente disolvieron las reglas sintácticas y semánticas para la vinculación entre la vida y la muerte $y$, en consecuencia, también dejaron sin fundamento las condiciones a través de las cuales los significados de 'vida' y 'muerte' pueden ser interpretados de forma ética.

En la formulación de una ética de la resistencia se realiza una crítica de la cultura. Según el pensador frankfurniano, "Toda la cultura después de Auschwitz, junto con la crítica contra ella, es basura" (Adorno, 1975, p. 367). En la reflexión ética se logra mostrar que la cultura ha sido cómplice de la barbarie porque integró el mal en expresiones artísticas y literarias que incrementaron la indiferencia respecto a lo sucedido. Adorno lo ejemplifica de la siguiente manera: "Hombres de reflexión y artistas han dejado más de una vez constancia de una sensación de cierta ausencia, de no entrar en el juego; es como si ellos no fuesen en absoluto ellos mismos, sino una especie de espectadores" (363). Auschwitz fue el lugar del fracaso de la cultura: "El hecho de que Auschwitz haya podido ocurrir en medio de toda una tradición filosófica, artística y científico-ilustradora encierra más contenido que el de que ella, el espíritu, no llegara a prender en los hombres y cambiarlos" (366). Adorno propone esta interpretación no solo con la intención 
de ilustrar este momento de crisis de la cultura, lo hace para indicar que la cultura y sus expresiones pueden resignificarse para que el sufrimiento tenga un lugar, un momento de atención. El simple hecho de que quien sufre pueda expresarse, es suficiente para justificar las expresiones culturales. Según Tafalla, "Por culpables que sean la literatura, la música o el arte los seguimos necesitando, porque no tenemos nada más con que enfrentarnos a la barbarie y recuperar las voces de las víctimas" (2003, pp. 258-259).

En este novedoso escenario de significación, la muerte deja de ser una categoría biológica y comienzan a plantearse sus posibles transformaciones, pues "[...] la forma en que la conciencia se resigna a la muerte varía según las condiciones concretas, y este cambio puede llegar a afectar a la misma esencia" (Adorno, 1975, p. 371).

Para Adorno, en el problema de la experiencia de la muerte no puede desconocerse el lugar que ocupa el dolor y el sufrimiento, pues allí se señala que el sentido de la negación se propone a partir del dominio que tiene la muerte sobre la vida, a través de diversas experiencias que suceden en el proceso de morir. La muerte y la acción de morir no se pueden separar porque, precisamente, la pérdida de significación de la muerte sucede cuando se desconoce que su experiencia, así como la de la vida, no son un asunto generalizable, sino que se trata de un hecho individualizable (cfr. Bernstein, 2001, p. 379). Para Adorno, lo que hace de la muerte un nuevo objeto de especulación metafísica es la decadencia de la experiencia de la vida.

Con base en lo anterior, Adorno considera que Auschwitz no solo es el lugar donde murió el individuo, sino el ejemplar de una especie (cfr. Adorno, 1975, p. 362). Allí la muerte es una experiencia individualizada que se opone a la vida y a la posibilidad de la narración. "Ya no queda posibilidad alguna de que entre en la experiencia vital de los individuos como algo concorde con el curso de su vida" (Adorno, 1975, p. 362). En Auschwitz a los seres humanos se les ha expropiado el derecho a su propia muerte porque en la industria del exterminio se eliminó de manera sistemática "lo propio", "la individualidad". Siempre vida y muerte estaban conectadas. Pero, en el desenlace de los sucesos de la barbarie, se ha superado el sentido de un proceso y, por ende, se ha quedado sin resultado: "Con el asesinato administrativo de millones de personas, la muerte se ha convertido en algo que nunca había sido temible de esa forma" (1975, p. 362).

Podría sospecharse que, así como nos comportamos con otros seres humanos e incluso con otras criaturas, igual lo hacemos con nosotros. Nos cobija la indiferencia, "ciegos ante el dolor". El espacio que nos separa de los otros tiene el mismo significado en la que no tiene cabida el olvido. Si fuese así "Toda reificación es un olvido" (Horkheimer y Adorno, 1998, p. 275), esta expresión expone el peligro que conllevaría si la muerte fuese negada como experiencia y solo se 
viese como el resultado de industrialización de la misma. Según Bernstein esta declaración es la expresión de una idea de ética que se aproxima a las concepciones de conocimiento teleológicas, es decir, que el pasado no puede desligarse de la fuente de su validez — la experiencia humana—, pues eso sería emplear de forma instrumental los intereses del presente y el futuro, lo cual trae como consecuencia la imposibilidad de cambio y transformación. Lo que se olvidaría, según la interpretación de Bernstein, no solo es el pasado, sino la posibilidad de lucha, el reconocimiento del sufrimiento y la valoración constitutiva del pasado como un camino para el aprendizaje. Si existiera una verdad previamente determinada y fija, implicaría aceptar que la historia y la experiencia del dolor interponen un límite infranqueable. Se trataría de una afirmación del olvido, de la expresión de una especie de anestésico epistemológico que aísla y adormece a los seres humanos respecto al dolor de otros (cfr. Bernstein, 2001).

Siguiendo a Bernstein, si solo se puede interpretar que la relación con los demás se lee a partir de una verdad lograda y determinada, que desconoce la experiencia del sufrimiento en el otro, entonces, más allá de este, no hay elemento para pensar la postulación de una verdad presente que emerja de un residuo moral que le confiera sentido, con base en la memoria, en la reivindicación del no olvido y de la experiencia de la muerte y del sufrimiento.

En este sentido, el materialismo en Adorno no se limita a una visión en el ámbito epistemológico, sino que se acerca a la corporalidad y la experiencia de muerte del sujeto. Es decir, la razón transita de un formalismo netamente epistémico hacia una proximidad con aquello que le permite conocer. El reconocimiento del sujeto no pasa por la noción de espíritu, como lo categorizó el idealismo hegeliano, sino por un cuerpo ubicado en un espacio y tiempo, que siente, que se percibe frágil, efímero y mortal (cfr. Tafalla, 2003, p. 165). Así, lo que el sujeto ha recuperado con el materialismo adorniano ha sido el lugar que ocupan, entre otros factores, los sentimientos y las emociones respecto a su constitución. En Mínima Moralia se afirma, "Más le convendría a la filosofía buscar en la contraposición de entendimiento y sentimiento la unidad de ambos: una unidad moral" (Adorno, 1998, p. 199, aforismo $\left.\mathrm{n}^{\circ} 127\right)$.

El ser humano, en cuanto sujeto moral, no se concibe únicamente como un ser racional, sino que es "[...] un cuerpo en el que la razón convive con una pluralidad de instintos, impulsos, deseos, afectos, pasiones y los conflictos que entre ellos existan" (Tafalla, 2003, p. 171). Lo que fundamenta la acción moral no es una voluntad racional, como postuló Kant, sino el impulso que surge del cuerpo porque ya no es aceptable que se legitime por una sola mirada de la razón el desconocimiento de lo corporal, de la sensibilidad y de la proximidad hacia los otros, ya que la moralidad no depende del cálculo racional, sino de la vinculación con el dolor de los demás. 
Bernstein contempla que el concepto de racionalidad se amplía por esta nueva aproximación del problema moral. La verdad no es un asunto de proximidad unidireccional entre el concepto y objeto. En correspondencia con la no identidad existe la posibilidad de conferirle significado a una no proximidad porque, por ejemplo, en el imaginario del niño el error, la no verdad, la no afirmación, plantean un camino para pensar la realidad de una manera distinta: "[...] su error funda el modelo de la experiencia de un concepto que al fin sería el de la misma cosa y no el miserable resto extraído de ella" (Adorno, 1975, p. 373).

El establecimiento de una relación entre el error y la verdad se podría lograr, como piensa Bernstein en la superación de una ilusión que, en lo real, solo se ha conceptualizado con base en las facultades y los principios de la razón. Solo así puede instituirse una verdad contundente que se expresa en la externalización del error y la verdad. Al sostener que el error pertenece a la verdad, la verdad está ligada a la trayectoria de su aparición (cfr. Bernstein, 2001, p. 337). En la superación de la ilusión ya no se habla de una sola verdad, sino de múltiples manifestaciones y momentos que, aunque pueden percibirse como incompletos, otorgan nuevas formas de interpretar la experiencia humana, particularmente cuando se aproximan a la experiencia del sufrimiento y del dolor.

Como afirmó Walter Benjamin, la ilusión de la verdad se aproxima al discurso de la información, mientras que la diversidad, la multiplicidad de la verdad, puede rastrearse en el mundo de la narración: narrar implica reconocer experiencias de vida y la capacidad para intercambiarlas, asunto que está deslegitimado por un mundo del consumo en el que solo cuenta lo que es contado como información. Según Benjamin:

La escasez en que ha caído el arte de narrar se explica por el papel decisivo jugado por la difusión de información... Cada mañana nos instruye sobre las novedades del orbe. A pesar de ello somos pobres en historias memorables. Esto se debe a que ya no nos alcanza acontecimiento alguno que no esté cargado de explicaciones. Con otras palabras: casi nada de lo que acontece beneficia a la narración, y casi todo a la información. Es que la mitad del arte de narrar radica, precisamente, en referir una historia libre de explicaciones (1998, p. 117).

En la narración, en sentido adorniano, se manifiestan formas de no olvido y la normatividad surge como nueva forma de narración y de interpretación ética que brota como un nuevo "[...] refugio para la esperanza" (Adorno, 1975, p. 381), que consiste en que todas las imágenes de reconciliación entre el concepto y el objeto adquieren sentido a través del principio de no identidad. 
Es importante reconocer que a partir de Adorno el lenguaje y la narración son determinantes para una idea de ética después de Auschwitz porque quien ha sufrido necesita expresarse. Se trata de una expresión en clave negativa porque mediante la jerarquización del sujeto sobre el objeto, los grandes sistemas conceptuales y sus conceptos se habían convertido en "[...] la cosificación de un olvido" (Tafalla, 2003, p. 83). En la incorporación de la ética, el lenguaje posibilita conocer el objeto y tener una esperanza para superar su aporía.

Según Bernstein cuando en Dialéctica Negativa se afirma que pensar es identificar, se está planteando no solo la crítica de un pensamiento centrado en la identidad, sino la relevancia del cuestionamiento que percibe el mundo siempre como nuestra idea de mundo, que los hechos son una sombra de la sintaxis, que la forma habitual de la aparición del mundo como algo ofrecido por el pensamiento es de alguna manera "inalienable", a pesar de que la no identidad es el têlos de toda actividad conceptual que se opone a la afirmación de un orden conceptual coherente, determinante y terminado. El mundo tal como se comprende es una apariencia necesaria, que responde a una práctica cognitiva y lingüística de rutinas prestablecidas (cfr. Bernstein, 2001, p. 346). Por esta razón, frente a la posición kantiana respecto a la posibilidad de conocer lo nouménico, en el sentido que lo plantea su crítica, se proyecta una alternativa para el eje comunicativo del lenguaje: así como el mundo se conoce a través de los fenómenos, igualmente ese conocimiento puede ser puesto en cuestión porque en lo nouménico, en el 'en sí mismo', el lenguaje se plantea como el reflejo de un mundo colapsando, carente de sentido y, a su vez, como el imperativo para que la última palabra de la historia no sea la del victimario, la del cálculo y las prácticas administrativas que plantearon la muerte como única alternativa posible (cfr. Bernstein, 2001, p. 347).

El problema de la relación verdad-error cumple un papel determinante para un conocimiento que se adecua a la situación que genera la no identidad. Es decir, el sentido de experiencia indica que el conocimiento no parte de conceptos abstractos, sino que su lugar de entronque está en el aquí y ahora. De este modo, lo que ha de ser conocido en sí mismo es un estado de asuntos atemporales e incondicionales que no tiene fijación conceptual estática (cfr. Bernstein, 2001, p. 338). Al respecto se afirma en Dialéctica Negativa:

La componente de autonomía e irreductibilidad en el espíritu pudiera muy bien concordar con el primado del objeto. En cuanto el espíritu llama por su nombre las cadenas en que cae al encantar a otros, se convierte hic et nunc en autónomo; donde esto ocurre él es, y no la entrampada praxis, el que anticipa la libertad (Adorno, 1975, p. 389). 


\subsection{Metafísica Negativa}

En el estudio realizado por Adorno se observa que el camino ya no es la absolutización que el idealismo hace de las concepciones metafísicas. Lo anterior no significa que Adorno desconozca la importancia de la reflexión teórica, sobre todo en asuntos prácticos. Sin duda, el problema de la libertad es fundamento de lo teórico, pues "[...] nace del conocimiento y se desarrolla con la actitud crítica" (Tafalla, 2003, p. 97). En la perspectiva crítica, el concepto de libertad se postula como una conciencia crítica que permite resistir ante una realidad que se presenta como praxis falsa, dado que

La misma autorreflexión afecta incluso las tesis del primado de la razón práctica, que llega en línea recta de Kant a Marx a través de los idealistas. La dialéctica de la praxis exigiría asimismo abolición de praxis, de la producción por la producción, fachada universal de una praxis falsa. Tal es la razón materialista de los rasgos que se revelan en la dialéctica negativa contra la doctrina oficial del materialismo (Adorno, 1975, p. 389)ㄱ.

Si ha habido una degeneración de la conciencia, ha sido precisamente por su incapacidad para la reflexión crítica sobre sí. En este sentido, no es suficiente que se piense en lo afirmativo, en lo idéntico; se requiere de un lenguaje, de unas prácticas, de una reflexión en armonía con lo diferente, que se exprese en su tono, porque, según Adorno, la diferencia permite pensar dialécticamente la identidad, y posibilita que esta cambie cualitativamente (cfr. Adorno, 1975, p. 152).

Según Bernstein, en el conocimiento de la no identidad es viable una aproximación a la identidad porque la teoría y la praxis no se miran independientemente sino como ejes conceptuales que se relacionan (cfr. 2001, p. 343). Se trata de una identidad no predicativa o demostrativa, en sentido teórico, pues se construye y deriva a partir de la experiencia cotidiana de los seres humanos. En este sentido, hay una comprensión intransitiva del conocimiento que se encuentra al final de la reflexión y no al inicio. La ejemplificación y la narración que valida la memoria es la manera adecuada para comprender el significado de esta forma de identidad intransitiva. Las inscripciones y marcas sensibles de la crueldad, por ejemplo, se asemejan a otras expresiones crueles en las cuales los seres humanos son miméticamente parecidos entre sí.

\footnotetext{
${ }^{7}$ Para Zamora "el concepto adorniano de praxis ayuda a dotar de contornos precisos al ámbito en el que hoy se plantea la cuestión moral y a perforar los rígidos límites de la filosofía práctica” (2004, p. 249). Por consiguiente, la praxis se convierte en el elemento que determina el discurso moral de Adorno. Su carácter crítico discrepa de las normativas morales tradicionales que reafirman la tendencia dominante hacia conductas de tipo individualistas y figuras argumentativas que supuestamente los fundamenta. Tales normativas suponen sujetos capacitados para una vida moral dentro de un orden social perfecto. Logrando incapacitar al mismo tiempo las normativas establecidas por imposibilitar percibir la fragilidad moral frente a fuerzas sociales destructivas al que el sujeto constantemente se expone.
} 
De acuerdo con la propuesta de Adorno, la crueldad se puede considerar finalmente a partir de dos horizontes: lo que tienen en común todos los actos crueles — se refiere a la experiencia-y, de manera intensiva, a través de un ejemplo que se refiera a lo que la crueldad misma es la que se refiere al concepto. La idea es superar la transitividad entre el concepto y la experiencia porque allí se supera una identidad que ha desconocido el dolor y el sufrimiento que ha traído la crueldad en sí misma. Ya no es significativo conceptualizarla; ahora la mirada se dirige a la experiencia sufriente y dolorosa que merece ser reconocida porque tiene nombres, rostros, formas, historias y expresiones que han sido silenciadas ${ }^{8}$.

Con base en lo anterior, se confirma la crítica al hecho de que en la filosofía tradicional la historia ha sido comprendida en el marco de una metafísica idealista:

Una metafísica falsamente resucitada cultiva en lo que llama historicidad un concepto ahistórico de historia. Esta tendría que servir de base para exponer el acuerdo del pensamiento ontológico con el naturalista, del que aquél se distancia con tanto celo [...] La pretensión ontológica de hallarse por encima de la divergencia entre naturaleza e historia es un engaño. La historicidad que se abstrae de la realidad histórica es indiferente al dolor (Adorno, 1975, p. 358).

Sin duda, Adorno se opone a una metafísica idealista que invisibiliza o se muestra esquiva respecto al sufrimiento particular, el carácter discontinuo de las vidas arruinadas, y que convierte el sufrimiento y la derrota en su victoria porque solo observa la historia como un resultado del progreso que en relación con las víctimas las mira, por ejemplo, como un recuerdo más de su lógica, por cuanto ellas hacen parte de su despliegue y desarrollo (cfr. Bernstein, 2001, p. 377). Es imposible que el salvajismo contra los seres humanos en escala sideral quepa en un relato afirmativo de corte metafísico. El pensamiento de Adorno, en este sentido, es refinado porque en la reivindicación de la situación de individualidades particulares destaca una particularidad de la historia y sus contradicciones que se actualiza en Auschwitz y sus manifestaciones contemporáneas.

Según Tafalla, "[...] uno de los rasgos que nos hace humanos [...] es el cuidado hacia los muertos, los entierros rituales, las tumbas, la construcción de cementerios" (2003, p. 243). Pensar en la historia en una perspectiva no idealista permite vincular la problematización sobre la praxis humana a través de la solidaridad, el sentido de la memoria y el compromiso con las víctimas. En cierto sentido, la memoria es una expresión de la compasión y solidaridad con todos los seres humanos porque los sucesos de la historia, en cierta medida, hacen que la humanidad en su totalidad

\footnotetext{
${ }^{8}$ En el lenguaje matemático la ley de transitividad es útil para entender estas relaciones. Cuando se habla de intransitividad se hace referencia a la noción de transitividad negativa o de la desigualdad en la que las relaciones de equivalencia no se construyen a partir de la noción de igualdad ( $\mathrm{si} \mathrm{a}=\mathrm{b}$ y $\mathrm{b}=\mathrm{c}$, entonces $\mathrm{a}=\mathrm{c}$ ), sino de la desigualdad. Allí la expresión del lenguaje es múltiple y diverso.
} 
sea víctima9. Por eso en Dialéctica de la Ilustración se afirma: "Sólo el horror a la aniquilación [...] establece la relación justa con los muertos: la unidad con ellos, dado que nosotros somos, como ellos, víctimas de las mismas condiciones y de la misma desilusionada esperanza" (Horkheimer y Adorno, 1998, p. 257). En consecuencia, se replantea el lugar mismo de la filosofía.

La necesidad de dejar su elocuencia al dolor es la condición de toda verdad. $Y$ es que el sufrimiento es objetividad que pesa sobre el sujeto; lo que este experimenta como lo más subjetivo, su propia expresión, está mediado objetivamente (Adorno, 1975, p. 26).

Ahora el dolor es el impulso somático para otorgar sentido a la reflexión filosófica. Es uno de sus lugares de expresión porque "La voz del dolor es capaz de quebrar los discursos del principio de identidad y fragmentar los sistemas totalitarios" (Tafalla, 2003, p. 116).

El imperativo que se instituye después de Auschwitz exige a la filosofía acoger la experiencia del sufrimiento, que escuche a los que sufren, aprenda a pensar desde y con ellos, ya que solo así conseguirá comprender al sujeto en medio de unas condiciones sociales que superan toda instancia gnoseológica.

En este sentido, la moralidad solo es posible en la sociedad liberada (cfr. Adorno, 1975, p. 396). Las condiciones de injusticia que suceden en la dinámica de la 'vida falsa' se explican a partir de una práctica del mal que no ha surgido de la subjetividad. Por eso en el conjunto de la vida, en la experiencia del sujeto, se emana un imperativo universal que es negativo y no afirmativo como pretendía Kant (cfr. Tafalla, 2003, p. 100). La pregunta kantiana iqué debo hacer? es reformulada por Adorno por ¿cómo debo vivir?

\subsection{Filosofía moral negativa}

La dialéctica negativa parte del cuestionamiento del pensamiento de la identidad, y por eso el nuevo imperativo, como su reflejo, es una articulación ética del movimiento de la dialéctica negativa. Por esta razón, según Bernstein,

\footnotetext{
${ }_{9}^{9}$ Respecto a la compasión y la solidaridad, Zamora afirma: "El ámbito de la compasión es la moral individual y su demanda proviene de una humillación cuyo origen es el sufrimiento socialmente producido. No existe ninguna adecuación entre dicho sentimiento individual y la producción estructural de la humillación" (2004, p. 364). De este modo, habría ciertas dificultades para comprender la compasión con categoría moral porque está limitada al ámbito del sujeto particular y no la colectividad. Frente a esta tesis Adorno se encuentra en un problema complejo al tratar de dar carácter universal a una realidad propia del sujeto. Sería repetir la noción idealista al quedar demasiado abstracta. Sin embargo, en la urgencia de reacción frente a la catástrofe y la frialdad, la compasión y solidaridad se convierten en el impulso moral, como agitación espontanea, para enfrentar la injusticia. De este modo, es irrelevante su noción abstracta o idealista; de lo que se trata es una salida para romper con las condiciones sociales en las que el sujeto de halla y, por tanto, debe salir. Es un impulso somático modificado.
} 
el imperativo es "negativo" (2001, p. 417). Ahora el límite de la filosofía es la auto-crítica del concepto identitario. Consiste en un camino para recuperar la inteligibilidad de la experiencia reflexiva, las pretensiones de validez del concepto simple y la concepción de una idea de filosofía que rastrea la inteligibilidad y el sentido de la existencia. El nuevo imperativo es una declaración ética de la dialéctica negativa, como filosofía moral negativa que pretende buscar unas posibilidades reales para que en la contemporaneidad exista una opción para la vida que no se fundamente en el pensamiento de la identidad, pues este ha contagiado a las instituciones y las prácticas sociales de la vida humana (cfr. Bernstein, 2001, p. 418) ${ }^{10}$.

El nuevo imperativo plantea una reorientación, un modo de proceder y pensar que busca orientar nuestras acciones, no simplemente como una idea regulativa, sino como un compromiso real y efectivo con aquellos que sufrieron y sufren, cuyo origen se encuentra en el contacto con la agonía física de la experiencia del sufrimiento corporal.

Auschwitz y sus expresiones contemporáneas no deben repetirse, ningún otro ser humano debe ser expuesto a la humillación física, moral, material o emocional; ningún ser humano debe ser vulnerado en su dignidad. Evidentemente la individualidad es más que la integridad física, pero no se puede olvidar que en la integridad física hay un estado de existencia de cada individuo.

Sucesos como Auschwitz despiertan el aborrecimiento porque lo sucedido allí fue visto y sentido; se experimentó una especie la negación y destrucción del cuerpo. Es aberrante el sufrimiento ocasionado a la condición que incorpora la individualidad. Por eso el cuerpo, como experiencia de la individualidad, es una manifestación de la moralidad visible.

En la imagen de Auschwitz se ha destruido y consumido la idea de que la existencia humana es esencialmente buena a priori, o la posibilidad de no haber, a pesar del mal del sufrimiento que se ha producido, algún sentido en sí mismo para la vida porque este se deriva de un origen trascendente. Las nociones que se tengan de la idea de bien deben originarse en los sentimientos de horror, dolor, compasión y repugnancia que causa un hecho como Auschwitz. La idea de bien podría seguir siendo regulativa si pasa de la dimensión de la trascendencia a la que se vincula solidariamente con las víctimas, pues ellas son el horizonte de la moralidad. Son las víctimas quienes se constituyen en principio de trascendencia para la moral después de Auschwitz. En este sentido, la trascendencia mantiene su

\footnotetext{
${ }^{10}$ Según Bernstein, el espacio imaginario entre la posibilidad lógica y real en que se desarrolla la crítica está el espacio de las prácticas de arte moderno. Las prácticas artísticas actuales son prácticas materiales que producen "individuos auréticos" y, en esa medida, son el complemento de la razón dialéctica y el nuevo imperativo que demuestra la "posibilidad" de un conocimiento de la individualidad (cfr. Bernstein, 2001).
} 
sentido, si es que aún lo tiene, si se relaciona dialécticamente con lo inmanente y concreto (cfr. Bernstein, 2001, p. 376).

Con Auschwitz toda teodicea filosófica es replanteada en particular porque no hay lugar para la metafísica afirmativa. Si hubiese lugar para la teodicea, esta sería negativa cuya forma narrativa parte de la experiencia de las víctimas; para que exista un aprendizaje moral y social; para que tales cosas no vuelvan a suceder, pues ante la integración absoluta que emana de la práctica genocida, se paraliza nuestra capacidad para pensar en la sobrevivencia, en la medida en que la experiencia de la muerte 'sistemática' y 'administrada' trae como consecuencia el desencanto de la vida como vida humana. Este es el sentido de "Negatividad absoluta" que caracteriza a Auschwitz como teodicea negativa (cfr. Bernstein, 2001, p. 383).

Por consiguiente, según lo anterior, el punto de partida de un proyecto ético que se formula después de Auschwitz debe ser negativo. Como ética negativa se fundamenta en la reivindicación de lo diferente, lo superfluo, lo aparentemente insignificante para el pensamiento. Se ha constatado que una norma moral universal es la imitación, la apariencia, del principio de identidad planteado por el idealismo. Una norma universal es a priori, su tendencia es hacia el autoritarismo y el totalitarismo (cfr. Tafalla, 2003, p. 113). El sentido del nuevo imperativo categórico inscribe su fundamento moral en la no repetición del mal y no en una ley abstracta universal, pues reconoce en el sufrimiento corporal, de cualquier sujeto, una reacción moral que señala un horizonte de universalidad de la moral (cfr. Tafalla, 2003, p. 114).

La base del nuevo imperativo está en la historia, pues se propone en un momento, tiempo y lugar determinados. Según Tafalla, "[...] los dos nombres que contiene el imperativo categórico, Hitler y Auschwitz, despierta el recuerdo de otros hechos particulares, mientras que la formulación puramente abstracta se alejaría para siempre de la realidad" (2003, p. 63). El imperativo no está orientado a un sujeto gnoseológico, sino a individuos concretos históricamente situados. La memoria adquiere un protagonismo preponderante porque impide que se olvide el pasado, si realmente importa el presente y el futuro. La racionalidad no puede ser ahistórica, porque existe la posibilidad del olvido, y eso se paga con la repetición. Una filosofía de la memoria es la única posibilidad de rescatar lo olvidado, lo marginado (cfr. Tafalla, 2003, p. 195); es darle un lugar a la justicia porque en Auschwitz las víctimas no solo fueron violentadas físicamente, sino eliminadas para siempre de la historia.

Este proyecto moral es la constatación de una filosofía después de Auschwitz en construcción, en la cual se asume la expresión de un pensamiento acorde con la fragilidad humana, según los acontecimientos que devela la realidad histórica. La reflexión moral marca el horizonte de un proyecto que debe evitar que todo 
pensamiento y acción desconozca la importancia y la especificidad de la no repetición.

\section{Conclusión}

Meditaciones sobre la metafísica en Dialéctica Negativa expone las categorías que Adorno propone para una nueva idea de filosofía, ética y educación. Igualmente presenta una novedosa manera de estudiar y comprender las categorías de los diferentes sistemas de la razón que terminaron en la expresión de Auschwitz.

Auschwitz simplifica lo que la reflexión de la Teoría Crítica ha determinado como la anulación de la subjetividad y la metafísica en el pensamiento occidental. Por esta razón, la propuesta de Adorno radica específicamente en plantear un nuevo horizonte de sentido que orienta nuevas realidades, como parte fundamental de la reflexión epistémica, para la filosofía y la propuesta moral. Se trata de la realidad fáctica e histórica de los seres humanos.

El problema del pensamiento tradicional, según Adorno, consistió en haber quedado inmerso en una metafísica que, al asumir un carácter trascendental, discrepa de la realidad y como consecuencia se idealiza. En la negatividad; es decir, la facticidad, la historia, en los testimonios, en la narración que deviene de Auschwitz, aparece un nuevo horizonte de sentido para la filosofía y moral. Este nuevo horizonte parte de la idea de que todo proyecto de la razón comienza en la situación específica en la que se encuentra el hombre. De este modo, si el proyecto de humanización, como proyecto moral, tiene como meta la felicidad, esta idea de moral trasforma lo anulado por la racionalidad dominante con base en una nueva forma de pensar y actuar contra la barbarie.

La norma moral no debe tener categorías idealistas, de allí que el nuevo imperativo categórico nazca de la experiencia de Auschwitz. A partir de esta nueva categoría que pone a prueba toda forma de pensamiento, se entiende que existe un nombre y una práctica específicos que orientan el destino de los imperativos morales. Aunque Auschwitz manifieste una norma universal, este carácter no necesariamente es idealista. El imperativo es expresión de la catástrofe y representa toda manifestación de ella en cualquier lugar y momento histórico.

Auschwitz representa el nombre de un evento que puede cambiar el análisis de las distintas expresiones de barbarie en la actualidad. Es decir, Ruanda, Siria, Kosovo, Colombia, etc., son nombres que representan a Auschwitz, y Auschwitz es la especificación para que esos acontecimientos sean una especie de caleidoscopio que ilustra los fractales a través de los cuales se puede analizar críticamente en la actualidad el mal presente en ellos. 
La novedad de la fundamentación de la ética debe resignificarse a través de la autocrítica que el pensamiento hace de sí mismo. No se trata de construir un nuevo sistema de pensamiento, sino de salvar lo que se ha edificado a través de la historia. Pero, son los hechos, sentimientos, las víctimas, experiencias y lo que escapa al sistema impuesto por una metafísica de carácter idealista, los que exigen una nueva manera de comprender, no solamente la forma de hacer filosofía, sino de pensar la moral. Por esta razón, la moral se constituye bajo el principio de la no-identidad como novedad para evitar que Auschwitz tenga posibilidad de repetirse.

\section{Referencias}

Adorno, T. et al. (1965). La personalidad autoritaria. (D. Cymbler y A. Cymbler, trads.). Buenos Aires: Editorial Proyección.

Adorno, T. (1975). Dialéctica Negativa. (J. M. Ripalda, trad.). Madrid: Taurus.

Adorno, T. (1993). Sobre sujeto y objeto. En Consignas (pp. 143-158). (R. Bilbao, trad.). Buenos Aires: Amorrortu Editores.

Adorno, T. (1998). Minima Moralia: reflexiones sobre la vida dañada. (J. Chamorro, trad.). Madrid: Taurus.

Barahona, E. (1996). Razón, verdad y crítica: momentos epistemológicos en la Dialéctica de la llustración de M. Horkheimer y T. W Adorno. Anales del Seminario de Metafísica, 30, 167-184.

Benjamin, W. (1998). Discursos interrumpidos I. (J. Aguirre, trad.). Madrid: Taurus.

Bernstein, J. M. (2001). Adorno: Disenchantment and Ethics. Cambridge: Cambridge University Press.

Cho, D. (2009). Adorno on Education or, Can Critical Self-Reflection Prevent the Next Auschwitz? Historical Materialism, 17, 74-97.

Escobar, J. (2009). Mito y reconciliación. Sobre el concepto de mito en la Dialéctica de la Ilustración. Areté. Revista de filosofía, 21(2), 381-400.

Gandler, S. (2009). Fragmentos de Frankfurt. Ensayos sobre la teoría crítica. Ciudad de México: Siglo XXI Editores.

Geyer, C. F. (1985). Teoría Crítica. (C. De santiago, trad.). Barcelona: Alfa. 
Horkheimer, M. (1973). Crítica de la Razón Instrumental. (H. Murena y D. Vogelmann, trads.). Buenos Aires: Sur.

Horkheimer, M. (1986). Ocaso. (J. Ortega, trad.). Barcelona: Anthropos.

Horkheimer, M. (2000). Razón y autoconservación. En Teoría tradicional y teoría crítica (pp. 89-120). (J. López, trad.). Barcelona: Paidós.

Horkheimer, M. y Adorno, T. (1998). Dialéctica de la llustración: fragmentos filosóficos. (J. Muñoz, trad.). Madrid: Trotta.

López, P. (2011). Ocaso del individuo, recuerdo de lo vivo. Sujeto y naturaleza en Adorno. En J. Muñoz (ed.), Melancolía y verdad (pp. 33-70). Madrid: Biblioteca Nueva.

Muñoz, J. (2011). Melancolía y verdad. Invitación a la lectura de Th. W. Adorno. En J. Muñoz (ed.), Melancolía y verdad (pp. 13-24). Madrid: Biblioteca Nueva.

Schopenhauer, A. (2009). El mundo como voluntad y representación. (P. López, trad.). Madrid: Trotta.

Tafalla, M. (2003). Una filosofía de la memoria. Barcelona: Herder.

Zamora, J. (2004). Th. W. Adorno: pensar contra la barbarie. Madrid: Trotta. 